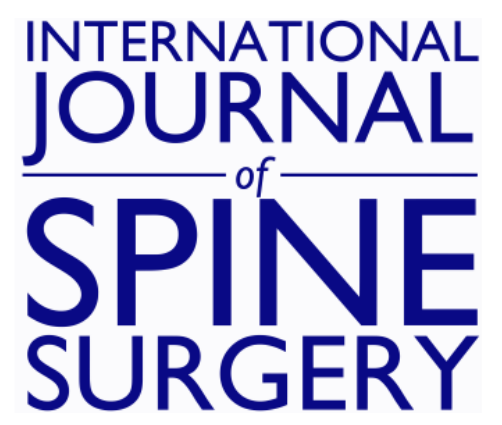

\title{
Measuring spinal canal size in lumbar spinal stenosis: description of method and preliminary results
}

Andrew Hughes, Serik K. Makirov and Valentin Osadchiy

Int J Spine Surg 2015, 9 ()

doi: https://doi.org/10.14444/2008

http://ijssurgery.com/content/9/8

This information is current as of April 26, 2023.

Email Alerts Receive free email-alerts when new articles cite this article. Sign up at:

http://ijssurgery.com/alerts 


\section{Measuring spinal canal size in lumbar spinal stenosis: description of method and preliminary results}

Andrew Hughes, MD, ${ }^{1}$ Serik K. Makirov Ph.D, ${ }^{1}$ Valentin Osadchiy Ph.D ${ }^{2}$

${ }^{1}$ Orthopedic Surgery, RMAPE, Moscow, Russia, 2 National University of Science and Technology (MISIS), Moscow, Russia

\section{Abstract}

\section{Background}

Lumbar spinal stenosis is a pathological condition of the spinal channel with its concentric narrowing with presence of specific clinical syndrome. Absence of the clear unified radiological signs is the one of the basic problems of the lumbar spinal stenosis.

\section{Purpose}

The authors seek to create method of assessment of the spinal canal narrowing degree, based on anatomical aspects of lumbar spinal stenosis.

\section{Study Design}

Development of diagnostic criteria based on analysis of a consecutive patients group and a control group.

\section{Methods}

Thirty seven patients (73 stenotic segments) with mean age 62,4 years old were involved in the study. Severity of clinical symptoms has been estimated by the measuring scales: Oswestry Disability Index (ODI) and Swiss Spinal Stenosis Questionnaire (SSQ). Mean number of the stenotic segments was 1.97. For all patients 8 radiological criteria have been measured. In the control group have been included 37 randomly selected patients (volunteers) in mean age of 53,4 years old without stenosis signs and narrowing of the spinal canal on the MRI imaging (73 segments total). Measurements were performed at the middle of intervertebral disc and facet joints level.

\section{Results}

For description of the state of spinal canal we offer the coefficient: ratio of the lateral canals total area to the crosssectional area of the dural sac ("coefficient of stenosis"). Comparison of mean values of "coefficient of stenosis" for main and control groups showed statistically significant differences $(t=-12,5 ; p<0.0001)$. Strong statistically significant correlation with the ODI and SSS scales was revealed for the obtained coefficient $(\mathrm{p}<0.05)$.

\section{Conclusions}

In our study new method of assessment of the spinal canal narrowing degree has been applied. Promising results have been obtained in a small group of patients. It is necessary to check the data on a large sample of recommendations for its clinical application.

KEYWORDS: LUMBAR SPINAL STENOSIS, COEFFICIENT OF STENOSIS, RADIOLOGICAL CRITERIA

VOLUME 9 ARTICLE 3 DOI: 10.14444/2008

\section{Introduction}

Lumbar spinal stenosis is a pathological condition of the spinal canal with its concentric narrowing and presence of specific clinical syndrome. Absence of the clear unified radiological signs is the one of the basic problems of the lumbar spinal stenosis. Spinal stenosis divides into lateral recess stenosisand spinal canal stenosis, because of topographical anatomy of involved spinal canal's structures. But method of assessment of the spinal canal, based on pathological process localization relative to its topographical 
anatomy is absence. Thus, Schizas et al., ${ }^{1}$ described a 7 -grade classification based on the morphology of the dural sac as observed on T2 axial magnetic resonance images based on the rootlet/cerebrospinal fluid ratio. He found no correlation between stenosis grade or DSCA and baseline Oswestry Disability Index or surgical result. The authors mention a control group; however, they do not give any information on the number of volunteers. Moreover, authors didn't use Swiss Spinal Stenosis Questionnaire for estimate patients' state.

We proposed a new method of assessment the spinal canal narrowing degree, based on the anatomical aspects of the lumbar spinal stenosis and established its correlation with the clinical picture of the disease.

\section{Materials and methods}

In our study 37 patients,in mean age of 62,4 years old (21 to 84): 23 women (62,2\%) and 14 men (37,8\%) with L1 - L5 stenotic segments, have been involved. Diagnosis "lumbar spinal stenosis" was established by the MRI imaging: a segmental narrowing of spinal canal in comparison with other unchanged segments, and the typical clinical signs of the disease. ${ }^{2}$ Severity of clinical symptoms has been estimated by the measuring scales: Oswestry Disability Index (ODI) and Swiss Spinal Stenosis Questionnaire (SSQ). Mean number of the Stenosis segments was 1.97 (singlelevel - 13 patients (17.8\%), double-level - 14 (19.2\%), triple-level - $8(11 \%)$, four-level - 2(2.7\%)) - 73 segments total. In the control group have been included 37 randomly selected patients (volunteers) in mean age of 53,4 years old (29 to 67) without stenosis signs and narrowing of the spinal canal on the MRI imaging (44 segments total).

For assessment of the spinal canal we designed a metrical system that is quantification of the stenosis level, based on estimation of cross sectional area of spinal canal within the confines of dural sac and lateral canals (RU patent \#2014108612 from 06.03.2014). The proposed method is following. After medical history collection and the physical examination, severity of the disease has been assessed using questionnaires ODI and SSQ. A cross sectional area of dural sac has been determined on coronal
MRI scan; the cross sectional area of left and right lateral canals has been determined according to anatomical landmarks: medial border of lateral canal is lateral wall of dural sac, upper border - body of vertebra, lower border - anterior pars intraarticularis, lateral border - foramen intravertebralis. All area values have been evaluated in $\mathrm{mm}^{2}$ and approximated to whole numbers. For simplification of statistical calculation we also introduced the concept of sum of cross sectional areas of lateral canals. Measurements of either linear, or area values have been made in ImageJ $1.47 \mathrm{v}$ (Wayne Rasband, National Institutes of Health, USA).

Thus, for all segments 9 radiological criteria have been measured (Figure 1 and Figure 2):

- Cross sectional area of dural sac;

- Cross sectional area of left and right lateral canals (including total);

- Total cross sectional area of dural sac and lateral canals;

- Anterio-posterior diameter of dural sac;

- Transverse diameter of dural sac;

- Ligamentous interfacet distance;

- Depth of the lateral recess;

- Lateral recess angle;

- Level of measuring.

The linear pair correlation has been counted for all criteria. Area values have been adopted as dependent variables, linear values - as their responses. The re-

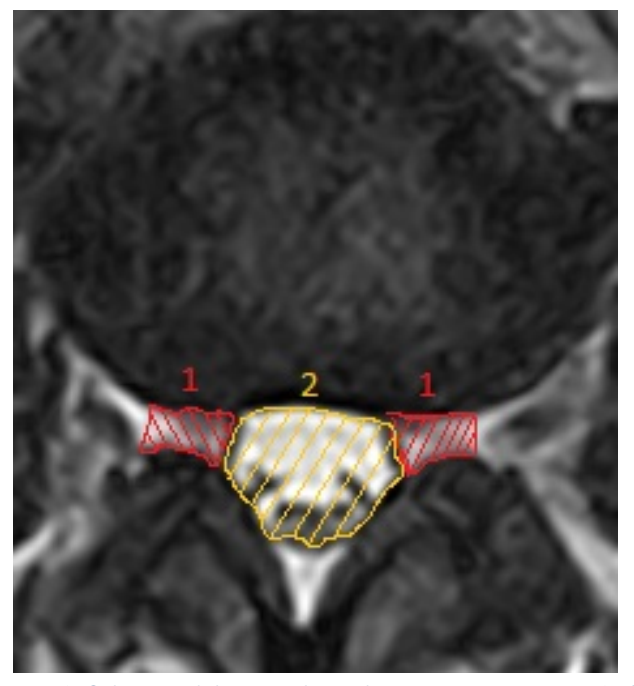

Fig. 1. Scheme of the spinal canal areas measurement: 1. Cross-sectional area of lateral channel; 2 . Cross-sectional area of dural sac. 
gression equations have been complied, basing on linear correlation.

The ratio of summary cross-sectional areas of lateral canals to cross-sectional area of dural sac has been calculated for every stenotic segment. This parameter we called "Coefficient of Stenosis". Value of this coefficient was compared with a control group values.

For evaluation multilevel lumbar spinal stenosis we used simple average value of "Coefficient of Stenosis", we called "Mean Coefficient of Stenosis". This value counted for each of the 37 patients from main group.

Then, group of 37 patients has been divided on 3 subgroups according to diapasons of value "Coefficient of Stenosis" (see section "Results") with parameters "ODI score", "SSQ score", "Mean Coefficient of Stenosis". Statistical analysis of the obtained data has been performed.

\section{Results}

Matrix of coefficient linear pair correlation of radiological criteria of spinal stenosis is presented at Tablet 1 . One can take that values greater than 0.3-0.5 suggest on association, values greater than 0.6-0.8 - on strong dependence. The linear values have the strongest correlation with area values

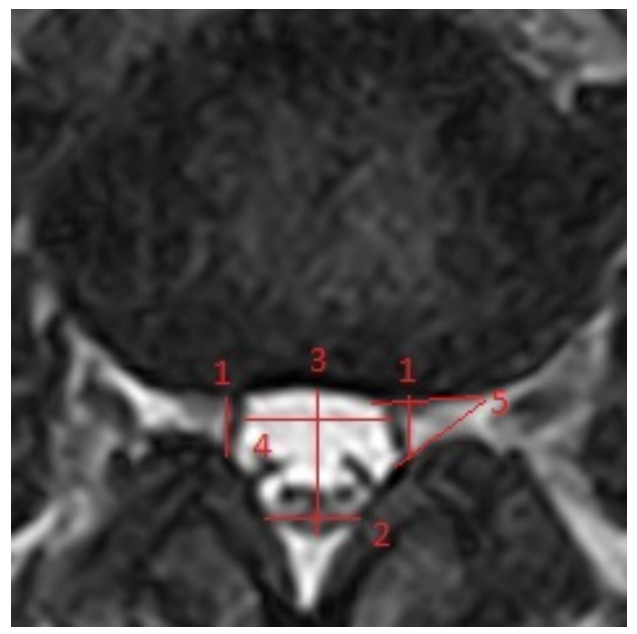

Fig. 2. Measurements of linear sizes of the spinal canal. 1. Depth of the lateral recess; 2. Ligamentous interfacet distance; 3. Anterio-posterior diameter of dural sac; 4. Transverse diameter of dural sac; 5 . Angle of the lateral recess.
(Table 1).

Thus, if area value is adopted as independent variables and linear values as their functions, one can derive the regression equations for evaluating mathematical relationships for presented criteria.

For total cross sectional area of dural sac and lateral canals $\left(S_{\text {tot }}\right)$ the regression equation would be:

$$
\begin{aligned}
& S_{t o t}=73.979-34.564 a+3.2642 a b-3.2988 c- \\
& 45.622 e^{*} * 10^{-6}-0.532541 a d+8.8397 e^{d *} 10^{-9}+ \\
& 1.6312 b x+2.821 a x+0.895555 d x-1.2874 x^{2}+781.36 e^{x} \\
& * 10^{-6}-0.112397 l e^{b}+4.6273 a l+1.7777 c l-0.705308 d l \\
& -4.1539 l e^{d *} 10^{-9}-0.0493349 l e^{l}
\end{aligned}
$$

(Multiple correlation coefficient: 0.97; Absolute average deviation: 6.33; Dispersion adequacy: 113.77;

Fisher's exact test: 0.0426 )

For cross sectional area of dural sac $\left(\mathrm{S}_{\mathrm{ds}}\right)$ :

$S_{d s}=20.97-0.232082 e^{b}+2.2805 a b-1.408 a c-$

$25.881 e^{c *} 10^{-6}-0.581787 b d+7.5121 e^{d *} 10^{-9}+$

$2.6178 b x+0.942024 d x-0.980777 x^{2}+904.05 e^{x} * 10^{-6}$

$+2.4068 a l-13.52 a l * 10^{-3}+1.5416 c l-0.948153 d l-$

$3.93881 e^{d *} 10^{-9}-140.67 l e^{x *} 10^{-6}$

(Multiple correlation coefficient: 0.96; Absolute average deviation: 6.15; Dispersion adequacy: 121.14; Fisher's exact test: 0.06 )

For total cross sectional area of lateral canals $\left(\mathrm{S}_{\mathrm{tlc}}\right)$ :

$$
\begin{aligned}
& S_{t l c}=7.8968-2.2562 a^{2}+0.277589 b c-17.456 e^{c *} 10^{-6} \\
& +0.818881 d+0.299036 b x+1.2592 a x-0.48867 c x+ \\
& 134.54 e^{x} * 10^{-6}-0.760372 b l+27.27 l e^{a} * 10^{-3}+ \\
& 0.820232 c l-0.125989 d l-0.019965 l e^{l}
\end{aligned}
$$

(Multiple correlation coefficient: 0.91; Absolute average deviation: 2.45; Dispersion adequacy: 14.2; Fisher's exact test: 0.1037 )

For cross sectional area of left lateral canal $\left(\mathrm{S}_{\mathrm{ll}}\right)$ :

$$
\begin{aligned}
& S_{l l}=12.385+1.0806 a b-1.8762 a^{2}+0.0630673 e^{a}+ \\
& 0.525861 b c-0.312815 a c-0.145376 c^{2}-0.575127 d+
\end{aligned}
$$


$0.295572 a d-0.602538 x-1.046 b l-0.0159611 l e^{b}+$ $0.80023+0.457975 \mathrm{cl}+140.46 l e^{d *} 10^{-12}+71.593 l e^{x} *$ $10^{-6}-0.0128876 l e^{l}$

(Multiple correlation coefficient: 0.85; Absolute average deviation: 1.96; Dispersion adequacy: 11.46;

Fisher's exact test: 0.2497 )

For cross sectional area of right lateral canal $\left(\mathrm{S}_{\mathrm{lr}}\right)$ :

Table 1. Linear pair correlation coefficients of spinal stenosis' radiological criteria
$S_{l r}=\left(-0.081946-0.0746809 b^{2}-0.0846632 a b-\right.$

$1.8533 e^{a} * 10^{-3}+0.344746 d-0.133269 a d+325.74 e^{d} *$ $10^{-12}+0.0874638 b x+0.307217 a x-0.0703017 c x-$ $0.0789677 b l+3.2052 l e^{b *} 10^{-3}+0.135448 c l-586.92 l e^{c}$ *10-9 $-131.99 l e^{d *} 10^{-12}-0.0765592 l x-4.4185 l e^{x} *$ $10^{-6}-1.63457 e^{\left.l * 10^{-3}\right)^{2}}$

(Multiple correlation coefficient: 0.87; Absolute average deviation: 1.45 ; Dispersion adequacy: 6.15;

Fisher's exact test: 0,2428)

\begin{tabular}{|c|c|c|c|c|c|c|c|c|c|c|c|c|c|}
\hline Criteria & $\begin{array}{r}\text { Total } \\
\text { cross- } \\
\text { sectional } \\
\text { area }\end{array}$ & $\begin{array}{r}\text { Cross- } \\
\text { sectional } \\
\text { area of } \\
\text { dural } \\
\text { sac }\end{array}$ & $\begin{array}{r}\text { Cross- } \\
\text { sectional } \\
\text { area of } \\
\text { left lateral } \\
\text { canal }\end{array}$ & $\begin{array}{r}\text { Cross-sec- } \\
\text { tional area } \\
\text { of right } \\
\text { lateral } \\
\text { canal }\end{array}$ & $\begin{array}{r}\text { Total } \\
\text { cross-sec- } \\
\text { tional area } \\
\text { of lateral } \\
\text { canals }\end{array}$ & $\begin{array}{r}\text { Anterio- } \\
\text { posterior } \\
\text { diameter } \\
\text { of dural } \\
\text { sac }\end{array}$ & $\begin{array}{r}\text { Transverse } \\
\text { diameter } \\
\text { of dural } \\
\mathrm{sac}\end{array}$ & $\begin{array}{r}\text { Ligamentous } \\
\text { interfacet } \\
\text { distance }\end{array}$ & $\begin{array}{r}\text { Depth } \\
\text { of the } \\
\text { right } \\
\text { lateral } \\
\text { recess }\end{array}$ & $\begin{array}{r}\text { Depth } \\
\text { of the } \\
\text { left lat- } \\
\text { eral re- } \\
\text { cess }\end{array}$ & $\begin{array}{r}\text { Angle } \\
\text { of the } \\
\text { right } \\
\text { lateral } \\
\text { recess }\end{array}$ & $\begin{array}{r}\text { Angle } \\
\text { of the } \\
\text { left lat- } \\
\text { eral re- } \\
\text { cess }\end{array}$ & $\begin{array}{r}\text { Level of } \\
\text { measuring }\end{array}$ \\
\hline $\begin{array}{l}\text { Total cross- } \\
\text { sectional } \\
\text { area }\end{array}$ & 1 & 0.97 & 0.75 & 0.71 & 0.84 & 0.69 & 0.57 & 0.64 & 0.54 & 0.65 & 0.07 & 0.02 & -0.51 \\
\hline $\begin{array}{l}\text { Cross-sec- } \\
\text { tional area } \\
\text { of dural sac }\end{array}$ & 0.97 & 1 & 0.64 & 0.62 & 0.73 & 0.73 & 0.53 & 0.64 & 0.53 & 0.62 & 0.1 & 0.01 & -0.52 \\
\hline $\begin{array}{l}\text { Cross-sec- } \\
\text { tional area } \\
\text { of left lateral } \\
\text { channel }\end{array}$ & 0.75 & 0.64 & 1 & 0.51 & 0.89 & 0.4 & 0.48 & 0.36 & 0.33 & 0.61 & -0.1 & 0.18 & -0.27 \\
\hline $\begin{array}{l}\text { Cross-sec- } \\
\text { tional area } \\
\text { of right lat- } \\
\text { eral channel }\end{array}$ & 0.71 & 0.62 & 0.51 & 1 & 0.84 & 0.34 & 0.48 & 0.48 & 0.53 & 0.4 & 0.01 & -0.1 & -0.28 \\
\hline $\begin{array}{l}\text { Total cross- } \\
\text { sectional } \\
\text { area of later- } \\
\text { al canals }\end{array}$ & 0.84 & 0.73 & 0.89 & 0.84 & 1 & 0.43 & 0.55 & 0.48 & 0.48 & 0.59 & 0 & 0.03 & -0.32 \\
\hline $\begin{array}{l}\text { Anterio-pos- } \\
\text { terior diame- } \\
\text { ter of dural } \\
\text { sac }\end{array}$ & 0.69 & 0.73 & 0.4 & 0.34 & 0.43 & 1 & 0.21 & 0.42 & 0.14 & 0.23 & 0.07 & -0.1 & -0.28 \\
\hline $\begin{array}{l}\text { Transverse } \\
\text { diameter of } \\
\text { dural sac }\end{array}$ & 0.57 & 0.53 & 0.48 & 0.48 & 0.55 & 0.21 & 1 & 0.59 & 0.48 & 0.53 & 0.26 & 0.15 & -0.31 \\
\hline $\begin{array}{l}\text { Ligamentous } \\
\text { interfacet } \\
\text { distance }\end{array}$ & 0.64 & 0.64 & 0.36 & 0.48 & 0.48 & 0.42 & 0.59 & 1 & 0.3 & 0.3 & 0 & -0.1 & -0.47 \\
\hline $\begin{array}{l}\text { Depth of the } \\
\text { right lateral } \\
\text { recess }\end{array}$ & 0.54 & 0.53 & 0.33 & 0.53 & 0.48 & 0.14 & 0.48 & 0.3 & 1 & 0.72 & 0.4 & 0.13 & -0.15 \\
\hline $\begin{array}{l}\text { Depth of the } \\
\text { left lateral } \\
\text { recess }\end{array}$ & 0.65 & 0.62 & 0.61 & 0.4 & 0.59 & 0.23 & 0.53 & 0.35 & 0.72 & 1 & 0.2 & 0.14 & -0.37 \\
\hline $\begin{array}{l}\text { Angle of the } \\
\text { right lateral } \\
\text { recess }\end{array}$ & 0.07 & 0.1 & -0.1 & 0.01 & 0 & 0.07 & 0.26 & 0 & 0.4 & 0.2 & 1 & 0.25 & -0.12 \\
\hline $\begin{array}{l}\text { Angle of the } \\
\text { left lateral } \\
\text { recess }\end{array}$ & 0.02 & 0.01 & 0.18 & -0.2 & 0.03 & -0.1 & 0.15 & -0.1 & 0.13 & 0.14 & 0.25 & 1 & -0.14 \\
\hline $\begin{array}{l}\text { Level of } \\
\text { measuring }\end{array}$ & -0.51 & -0.52 & -0.27 & -0.28 & -0.32 & -0.28 & -0.31 & -0.48 & -0.15 & -0.37 & -0.12 & -0.14 & 1 \\
\hline
\end{tabular}


Designation values for the above equations: a Depth of the right lateral recess; $b$ - Depth of the left lateral recess; $\mathrm{c}$ - Ligamentous interfacet distance, $\mathrm{d}$ -Transverse diameter of dural sac, $\mathrm{x}$ - Anterio-posterior diameter of dural sac, 1 - Level of measuring.

Following data of the "Coefficient of Stenosis" evaluating have been obtained for these two groups. In the main group in $90.3 \%$ of cases ( 69 segments) value of the coefficient was 0.24 and below $(0,05$ to 0,24$)$ In $9.7 \%$ (4 segments), the value of coefficient was 0.25 0.26 . Mean value of coefficient for main group was 0,18 with st. deviation 0,05 . For "Mean Coefficient of Stenosis" values has for main group was 0,090,26 (mean 0,18 ) with st. deviation 0,038 . For ODI scale mean value was $0.76(0.40$ to $0 ., 78)$ with st. deviation 0,092 ; for SSQ respectively - 0.96 (0.42 to $0.96)$, st. deviation 0.10 .

In the control group minimum value of the "Coefficient of Stenosis" was 0.30 and above in $94.3 \%$ of segments (39 segments); in 2 cases (4.8\%) value of the coefficient was $0.24-0.27$. Comparison of mean values of "Coefficient of Stenosis" for main and control groups showed statistically significant differences $(\mathrm{t}=-12.5 ; \mathrm{p}<0.0001)$. In control group scales ODI and SSQ didn't define.

This data may correspond to 4 variants of the spinal canal state (3 subgroups in main group):

1. From 0.19 and below - apparent spinal stenosis (Subgroup 1);

2. 0.20 to 0.24 - a clinically significant spinal stenosis (Subgroup 2);

3. 0.25 to 0.29 - a probable stenosis (Subgroup 3);

4. 0.30 and above - normal spinal canal (control Group).

According to these intervals main group has been divided into 3 subgroups (Table 2). In Subgroup 3 only one patient has been included, so statistical analysis has been made between Subgroup 1 and Subgroup 2. To evaluate differences between two independent samples we used Mann - Whitney U-test. Subgroup number of has been used as grouping variable. See Table 3.

\section{Discussion}

The lumbar spinal stenosis is the fairly common disease. Its incidence is about 1:1000 and this ratio has significantly increased in recent years due to the increase in life expectancy. ${ }^{3-5}$ With introduce of new diagnostically methods into clinical practice, new radiological criteria of spinal canal assessment have been proposed, as well as areas and levels of measuring. In recent years MRI has become "gold standard" in diagnostic of the lumbar spinal stenosis, due to its possibility to visualize Roentgen-negative soft tissues.

Table 2. Characteristics of Subgroups' 1-3 mean values
\begin{tabular}{|l|r|r|r|}
\hline & Group 1 & Group 2 & Group 3 \\
\hline Patients & 19 & 16 & 1 \\
\hline Mean CS & 0.15 & 0.21 & 0.26 \\
\hline Mean ODI & 0.62 & 0.59 & 0.4 \\
\hline Mean SSQ & 0.76 & 0.74 & 0.42 \\
\hline
\end{tabular}

Table 3. Mann-Whitney $U$ test for Subgroups 1 and 2 (generated in IBM SPSS Statistics 19)

\begin{tabular}{|c|c|c|c|c|}
\hline \multicolumn{5}{|c|}{ Ranks } \\
\hline & Subgroup No. & $\mathrm{N}$ & Mean Rank & Sum of Ranks \\
\hline \multirow{3}{*}{ ODI } & 1.00 & 20 & 21.93 & 438.50 \\
\hline & 2.00 & 16 & 14.22 & 227.50 \\
\hline & Total & 36 & & \\
\hline \multirow{3}{*}{ SSS } & 1.00 & 20 & 21.80 & 436.00 \\
\hline & 2.00 & 16 & 14.38 & 230.00 \\
\hline & Total & 36 & & \\
\hline \multirow{3}{*}{$\mathrm{mCS}$} & 1.00 & 20 & 10.50 & 210.00 \\
\hline & 2.00 & 16 & 28.50 & 456.00 \\
\hline & Total & 36 & & \\
\hline \multicolumn{5}{|c|}{ Test Statistics ${ }^{\mathrm{a}}$} \\
\hline & & ODI & SSS & $\mathrm{mCS}$ \\
\hline \multicolumn{2}{|c|}{ Mann-Whitney U } & 91.50 & 94.00 & 000 \\
\hline \multicolumn{2}{|c|}{ Wilcoxon W } & 227.500 & 230.000 & 210.000 \\
\hline \multicolumn{2}{|l|}{ Z } & -2.191 & -2.108 & -5.116 \\
\hline \multicolumn{2}{|c|}{ Asymp. Sig (2-tailed) } & .028 & .035 & .000 \\
\hline \multicolumn{5}{|c|}{ aGrouping Variable: Subgroup Number } \\
\hline \multicolumn{5}{|c|}{ ODI - Oswestry Disability Index. SSQ - Swiss Spinal Stenosis } \\
\hline
\end{tabular}


For quality research of one or another disease, sensitive and rational including criteria definition requires. However, for the lumbar spinal stenosis similar criteria still didn't develop.

Steurer et al. ${ }^{6}$ in their systematic review concluded about necessarily of well-defined, unambiguous radiological criteria of lumbar spinal stenosis to improve the quality of diagnostics and development of firm criteria for inclusion in clinical trials.

Genway et al. ${ }^{7}$ noted, that researchers use a variety of combinations of symptoms, clinical signs and radiological criteria for inclusion of patients in studies of lumbar spinal stenosis.

The North American Spine Society ${ }^{8}$ in their clinical recommendations noted, that medical visualization a key method in diagnostic of lumbar spinal stenosis, but they didn't denote specific radiological criteria.

The goal of our study - to create a accuracy, informative, easy and objective evaluation method spinal canal narrowing degree in lumbar spinal stenosis. The essence of the method is that on MRI in segments L1 - L5 with measuring linear dimensions on axial scans cross sectional area of dural sac and lateral canals are calculated by the above formulas. We didn't include narrowing of spinal canal on L5-S1 level in our study, because of this part of spinal column significantly differs from lumbar spine in anatomical and functional aspects.

Variables used our study have been selected from 15 studies by CT and MRI. Criteria and their critical values for stenosis are listed below.

Anterio-posterior diameter of dural sac - distance between middle of vertebral body and middle of basis of processus spinosus at border of dural sac. This criteria has been described in 3 works ${ }^{9-11}$. Critical value varies due to different zones of measuring ( $<10$ to $<15 \mathrm{~mm}$ ).

In certain study criteria "anterio-posterior diameter of spine canal" had been used, but the authors concluded that its diagnostic value was limited. Thus, Bolender et al. ${ }^{12}$ suggested, that this parameter had lower value, than assessment of contrast zone of dural sac on mielogramms (20\% vs $83 \%$ clear diagnosis). We think, that deformity of dural sac is more objective index of spinal stenosis, because compression neural elements itself causes clinical signs of stenosis. In the same time, narrowing spinal canal without deformity of dural sac doesn't mark of stenosis, because anatomy of spinal canal may vary in different patients.

Transverse diameter (size) of dural sac - distance between lateral borders of dural sac on the level of lateral canals. Criteria is evaluated in 2 studies.${ }^{5,13}$ Critical value for stenosis is $<15$ to $<16 \mathrm{~mm}$. Zones of measuring are different.

Cross-sectional area of dural sac - Criteria is evaluated in 7 studies. ${ }^{2,4,8,12,14-16}$ Zones of measuring are different. Critical value is $<75$ to $<130 \mathrm{~mm}^{2}$.

Intrafacet distance - distance between the inner surfaces of flaval ligaments on a line connecting the joint space of facet joints. Criteria is evaluated in 2 studies. ${ }^{9,17}$ Critical values are $<15$ to $<16 \mathrm{~mm}$. Zones of measuring are different.

Depth of the lateral recess - distance between the superior articular facet and the top part of the pedicle. Criteria is evaluated in 2 studies. ${ }^{6,18}$ Critical values are $\leq 3.6$ to $<2 \mathrm{~mm}$. Zones of measuring are different.

Lateral recess angle - the angle between the lines parallel to the floor and the roof of the lateral recess. Criteria is evaluated in 1 study. ${ }^{6}$ Critical value is < $30^{\circ}$.

Furthermore, we proposed 3 own radiological criteria: level of measuring; cross-sectional area of left and right lateral canal and their summary. All measurements were performed by manual selection of evaluating area, which is a significant drawback of the methodology, due to the possibility of mistakes and subjective interpretation of images. To minimize the possibility of error, all measures were made for three times, after which arithmetic mean value has been calculated. Thus, this technique requires significant improvements to increase validity. This will be the purpose of our future studies. 
As it's mentioned above, we used a fixed measurement level of vertebral canal: in the middle of the intervertebral disc and facet joints. Selecting the location of measurement is based on the position of the degenerative changes three-joint complex, that is defining stenosis in terms of its morphological substrate..$^{13}$ In addition, in this zone yellow ligament can be visualized, and one can evaluate the degree of canal narrowing when prolapse or hypertrophy. From a mathematical point of view, the selected zone is the mid-distance between the centers of adjacent vertebral bodies. If the lumbar vertebrae is numbered from 1 to 5 , the intermediate value measurement level L1 $\mathrm{L} 2$ is equal to the number of 1.5 , the level of L2 - L3 number 2,5 , etc. This parameter we include in regression equations as the independent variable, called "Level of measuring".

In general, segmental division of cross-sectional area of spinal canal is well-founded. As well known, in lumbar spine the form of spinal canal is committed to triangular. Therefore, the degree of stenosis in various zones ambiguous in terms of relative values. Lee at al. ${ }^{4}$ described topographical anatomy of lateral canal, dividing it into 3 zones: enter zone, middle zone, and exit zone. As it has been proved, lateral canal is a complex structure and topographical anatomy in its various zones is not equal. Consequently, measuring the area of a lateral canal as an independent structure is justified and it's necessary to accurately assess the degree of stenosis of the spinal canal as a whole.

To assess the narrative validity of all the selected criteria we used analysis of linear bivariate correlation coefficients. The table above clearly shows that the strongest correlation is observed between linear values and area parameters. At the same time, the correlation between linear variables is weaker. However, there is no significant correlation of criteria "the angle of the lateral recess" with other linear variables and area parameters. As the result, this criteria was excluded from the study as uninformative.

Next, we found a mathematical relationship that revealed correlation interactions with regression equations. Area parameters were taken as dependent variables, because the greatest number of strong correla- tions with linear values. Accordingly, the linear values were taken as a function of the dependent variable. In fact, we obtained significantly adequate mathematical model of spinal canal stenosis at the level of the lumbar spine.

Due to small sample size to eliminate effect of parties narrowing of the lateral canal on correlation analysis, we introduced the parameter «the sum of the areas of lateral canals», thereby separated areas of lateral canals from the central area. This reduced the measurement error and gave an opportunity to assess narrowing of the lateral canals of a whole and to compare it with those of the central area.

Attempts to create such coefficient have been already taken elsewhere. So, Laurencin et al. ${ }^{14}$ introduced Coefficient of Stenosis as the ratio of the cross sectional area of the dural sac in motion segment to cross-sectional area of the dural sac in stable segment. This coefficient is rather subjective due to evaluation stability of the segment on static MRI in the horizontal (non-physiological) position. Moreover, it does not allow for condition of lateral canals.

We proposed a coefficient, that evaluating ratio of areas into spinal canal on one level. Its estimation doesn't require difficult mathematical operations and invasive diagnostic methods. In general, we believe, the conception of a "normal" cross sectional area is incorrect. The cross sectional of the spinal canal is always associated with individual anatomical and constitutional features. We believe that "Coefficient of Stenosis" is more objective parameter of spinal canal narrowing, due to not relative but absolute area values.

Another important aspect in our study is evaluating correlation between "Coefficient of stenosis" and clinical symptoms of disease. Currently, there're much numeric scales and questionnaires designed for objectifying clinical evaluation of the patients symptoms. Cleland et al. ${ }^{19}$ in their study compared psychometric properties of most frequently used numeric scales and questionnaires in diagnostic of lumbar spinal stenosis. Authors concluded, that most adequate psychometric properties had been seen for Oswestry Disability Index, Modified Swiss Spinal 
Stenosis Questionnaire and Patient Specific Functional Scale. Although authors concluded about necessarily of future studies for evaluation their specificity. The modified Swiss Spinal Stenosis Scale is considered a "gold standard" for evaluation of severity lumbar spinal stenosis.

In our study we used Oswestry Disability Index and Modified Swiss Spinal Stenosis Scale. We didn't use Patient Specific Functional Scale, because it assesses the effectiveness of treatment in certain time intervals, and it 's design isn't suitable for our study. For evaluation of multilevel lumbar spinal stenosis we used simple average value of "Coefficient of Stenosis", we called "Mean Coefficient of Stenosis". It was necessary to compare the questionnaires values with the spinal canal narrowing degree.

As mentioned above, we compared results of ODI and SSQ scales for two subgroups of patient based on "Coefficient of Stenosis" intervals. For evaluate differences between this two independent samples we used Mann - Whitney U-test (Table 3). As one can see, mean rank for ODI and SSQ is higher in Subgroup 1, so clinical picture in this group is more severe. In the same time, Mean Coefficient of Stenosis (mCS) value is higher for Subgroup 2, so spinal canal narrowing degree is less in this group. Z-criteria for all parameters is normalized with $\mathrm{p}<0,05$, so we can sure in significance of differences between this two subgroups.

This data confirm significant correlation of "Mean Coefficient of Stenosis" with Oswestry Disability Index and Modified Swiss Spinal Stenosis Scale, in other words - correlations between clinical symptoms and radiological findings.

\section{Conclusion}

In our study we have been applied a new approach to determine optimal radiological criteria of a spinal canal narrowing - total cross sectional area of dural sac and lateral canals on middle of interveretebral disc and facet joints level. Therefore, for best clinical interpretation we proposed parameter "Coefficient of Stenosis" that had been obtained by a completely new method. Significant correlation has been found between "Coefficient of Stenosis" value and numeric scales/questionnaires data (Oswestry Disability Index and Modified Swiss Spinal Stenosis Scale), that confirms relation between clinical symptoms and radiological findings. Of course, this is only preliminary results obtained in small sample. It is necessary to check the data on a large sample of recommendations for the clinical application of the method.

\section{Further research}

1. It's necessary to increase the number of patients for simplification of equation without losing sensitivity and clarify of the correlation coefficients;

2. Correlation to the foreman vs. canal stenosis, investigate \% of radicular and axial pain, right vs. left should be examined;

3. The aim of this study was to analyze the parameters proposed to describe the sagittal plane MRI and explore their mathematical relationships. If the principle underlying this study will prove its worth, it will be used for further evaluation of the vertebral column;

4. Repeatability of the measurements should be investigated.

5. Mean coefficient of stenosis can't give relevant results in all cases, because each symptom of disease plays its own role in the clinical picture. In other words, the clinical picture of the disease is not the average of all symptoms. This problem requires the development of other mathematical solutions to solve.

\section{References}

1. Schizas C, Theumann N, Burn A, Tansey R, Wardlaw D, Smith FW, et al. Qualitative Grading of Severity of Lumbar Spinal Stenosis Based on the Morphology of the Dural Sac on Magnetic Resonance Images. SPINE: Lippincott Williams \& Wilkins; 2010. Volume 35, Number 21, p. 1919-1924. 2. Hall S, Bartleson JD, Onofrio BM, Baker HL Jr, Okazaki H, O'Duffy JD. Lumbar spinal stenosis. Clinical features, diagnostic procedures, and results of surgical treatment in 68 patients. Ann Intern Med; 1985. 
3. Grenier N, Kressel HY, Schiebler ML, Grossman RI, Dalinka MK. Normal and degenerative posterior spinal structures: MR imaging. Radiology; 1987.

4. Lee CK, Rauschning W, Glenn W. Lateral lumbar spinal canal stenosis: classification, pathologic anatomy and surgical decompression. Spine (Phila Pa 1976); 1988.

5. Strojnik T: Measurement of the lateral recess angle as a possible alternative for evaluation of the lateral recess stenosis on a CT scan. Wien Klin Wochenschr; 2001.

6. Steurer J, Roner S, Gnannt R, Hodler J. Quantitative radiologic criteria for the diagnosis of lumbar spinal stenosis: a systematic literature review. BMC Musculoskeletal Disorders; 2011.

7. Genevay S, Atlas SJ, Katz JN. Variation in eligibility criteria from studies of radiculopathy due to a herniated disc and of neurogenic claudication due to lumbar spinal stenosis: a structured literature review. Spine (Phila Pa 1976); 2010.

8. North American Spine Society: Evidence Based Clinical Guidelines for Multidisciplinary Spine Care: Diagnosis and Treatment of Degenerative Lumbar Spinal Stenosis. In. Burr Ridge, IL.: North American Spine Society; 2007.

9. Hamanishi C, Matukura N, Fujita M, Tomihara M, Tanaka S. Cross-sectional area of the stenotic lumbar dural tube measured from the transverse views of magnetic resonance imaging. J Spinal Disord; 1994.

10. Herzog RJ, Kaiser JA, Saal JA, Saal JS. The importance of posterior epidural fat pad in lumbar central canal stenosis.Spine (Phila Pa 1976); 1991.

11. Jönsson B, Annertz M, Sjöberg C, Strömqvist B. A prospective and consecutive study of surgically treated lumbar spinal stenosis. Part I: Clinical features related to radiographic findings. Spine (Phila $\mathrm{Pa}$ 1976); 1997.

12. Bolender NF, Schönström NS, Spengler DM. Role of computed tomography and myelography in the diagnosis of central spinal stenosis. J Bone Joint
Surg Am; 1985.

13. Kirkaldy-Willis $\mathrm{WH}$, Wedge $\mathrm{JH}$, Yong-Hing $\mathrm{K}$, Reilly J. Pathology and pathogenesis of lumbar spondylosis and stenosis. Spine (Phila Pa 1976); 1978.

14. Laurencin C, Lipson S, Senatus P, Botchwey E, Jones T, Koris M, Hunter J. The stenosis ratio: a new tool for the diagnosis of degenerative spinal stenosis. Int J Surg Investig; 1999.

15. Schonstrom N, Bolender N, Spengler D. The pathomorphology of spinal stenosis as seen on CT scans of the lumbar spine. Spine (Phila $\mathrm{Pa} 1976$ ); 1985.

16. Thomé C, Börm W, Meyer F. Die degenerative Spinalkanalstenose: Aktuelle Strategien in Diagnostik und Therapie. Deutsches Ärzteblatt; 2008. 17. Ullrich C, Binet E, Sanecki M, Kieffer S. Quantitative assessment of the lumbar spinal canal by computed tomography. Radiology; 1980.

18. Ciric I, Mikhael MA, Tarkington JA, Vick NA. The lateral recess syndrome. Avariant of spinal stenosis. J Neurosurg; 1980.

19. Cleland JA, Whitman JM, Houser JL, Wainner RS, Childs JD. Psychometric properties of selected tests in patients with lumbar spinal stenosis. Spine J; 2012.

\section{Disclosures}

The authors declare no financial disclosures.

\section{Corresponding Author}

Andrew Hughes, MD, orthopedic surgeon, postgraduate RMAPE. worfeva@gmail.com.

Published 24 March 2015.

This manuscript is generously published free of charge by ISASS, the International Society for the Advancement of Spine Surgery. Copyright @ 2015 ISASS. To see more or order reprints or permissions, see http://ijssurgery.com. 